\section{Michael Peterson}

is a partner with Booz \&

Company in Munich and London.

He serves clients in the broader communication and technology

industries, and focuses on

mobile markets and convergence

services across Europe. His areas

of expertise comprise strategy

development, specifically related

to Marketing and Sales as well as all customer-facing processes.

\section{Florian Gröne}

is a senior associate with Booz \&

Company in Berlin. He supports

telecommunications, media and

technology players in developing

market positioning strategy,

defining CRM strategy, operating

models and IT architecture

and improving performance in

customer-facing functions.

\section{Karsten Kammer}

is a senior associate with Booz \& Company in Munich. He primarily works with telecommunications and high-tech clients. His focus areas include sales effectiveness, growth, and innovation, as well as organizational design.

\section{Julius Kirscheneder}

is a senior associate with Booz \& Company in Munich and $a$ member of the communications, media and technology practice. He supports mobile and internet-related service providers in their strategic road map and focuses on customer-centric functions from product innovation to sales and service.

\section{Michael Peterson}

Booz \& Company

Zollhof 8

40221, Düsseldorf, Germany

Tel: +492113890140

Fax: +492113890300

Email: michael.peterson@booz.com

\section{Opinion Piece}

\section{Multi-channel customer management: Delighting consumers, driving efficiency}

\author{
Michael Peterson, Florian Gröne, Karsten Kammer \\ and Julius Kirscheneder \\ Received: 7th December 2009
}

\begin{abstract}
In today's maturing consumer markets, emphasis is shifting from straightforward sales to a more holistic approach to customer life cycle management, with a stronger emphasis on how sales are generated and service provided all along the customer journey. Effectively managing these different marketing, sales and service channels poses a significant challenge. Companies need new strategies, structures, processes and tools to deliver customer value across all channels. A multi-channel, integrative customer model that delivers customer value and significant return on investment $(\mathrm{ROI})$ requires both a strong understanding of customer preferences and behaviours and a robust IT architecture that supports the overarching customer relationship management (CRM) strategy. Even those organizations that have embraced the need for sophisticated multi-channel orchestration often still fall short in their execution. We offer strategic guidelines in four areas to ensure success with multi-channel orchestration. First, marketing operations need to explicitly define a channel strategy with respect to customer segmentation, the channel journey (how and where sales and services are delivered) and targeted incentives that reward multi-channel sales and service support. Secondly, marketers need to optimize the online channel, which is fast becoming the primary platform for accessing product and service information, and completing an ever-growing number of transactions. It is also the entry hub to other touch points; customers go online to contact the company or to find store locations or telephone numbers. Thirdly, companies need to build an IT foundation that underpins their CRM strategy. This CRM IT architecture needs to enable the transformation from vertical, single-channel operations to true horizontal business processes that deliver cross-channel integration. Fourthly, marketers can learn by example. Companies across the consumer products spectrum are experimenting with the multi-channel experience. Marketers
\end{abstract}


Keywords: customer service, sales, customer delight, multi-channel, customer lifecycle management, CRM

\section{Need to think 'multi-channel'}

\section{Cross-channel consistency and seamless hand-overs are key}

should broadly consider the best practices that they could adapt to their own industry. Journal of Direct, Data and Digital Marketing Practice (2010) 12, 10-15. doi:10.1057/dddmp.2010.16

\section{The new multi-channel customer interaction model}

Today's marketing executives understand the need to develop new customer interaction strategies, structures, processes and tools what Booz \& Company defines as the four pillars of profit-driven marketing. ${ }^{1}$

They are working hard to apply and optimize these pillars within their individual customer channels. But in an era when customers are increasingly well informed and communications savvy, this channel-bychannel approach is not enough: Today, businesses need a multi-channel strategy that offers consumers a seamless experience across all touch points, or they will miss an opportunity for customer value generation. A recent survey found that in Germany alone, businesses wasted more than $€ 1$ bn (US $\$ 1.5$ bn) a year in unproductive marketing — often due to a narrow focus on single channels.

When effectively executed, a multi-channel approach will smooth the relationship between customer and company and give management the capability to leverage all customer touch points to boost revenues, reinforce customer satisfaction and streamline sales and service costs.

\section{Follow the buying journey}

Cross-channel customer management starts with better customer understanding.

The more data points there are, the more opportunities marketing has to tailor a sales pitch and service proposition to delight the customer. ${ }^{2}$ This means companies need to compile and maintain a comprehensive customer profile along the buying journey, starting from the moment customers initially indicate interest, through the time they spend gathering information, to when they complete a transaction and seek post-sale support (see Figure 1).

The process that leads to a purchase usually combines multiple channels. Customers should receive consistent information and offers across all channels. In a true multi-channel environment, marketing departments know customer preferences, interests and interaction history, regardless of whether customers are shopping in a store, calling the company or visiting its website.

Post-sale service should similarly offer seamless interactions via the customer's preferred interaction platform. For example, a customer should be able to speak with a call centre representative about returning a product and then drop off that product at the nearest retail location with a store clerk who has full visibility into the history of that customer's previous interactions. 


\section{装. Peterson, Gröne, Kammer and Kirscheneder}

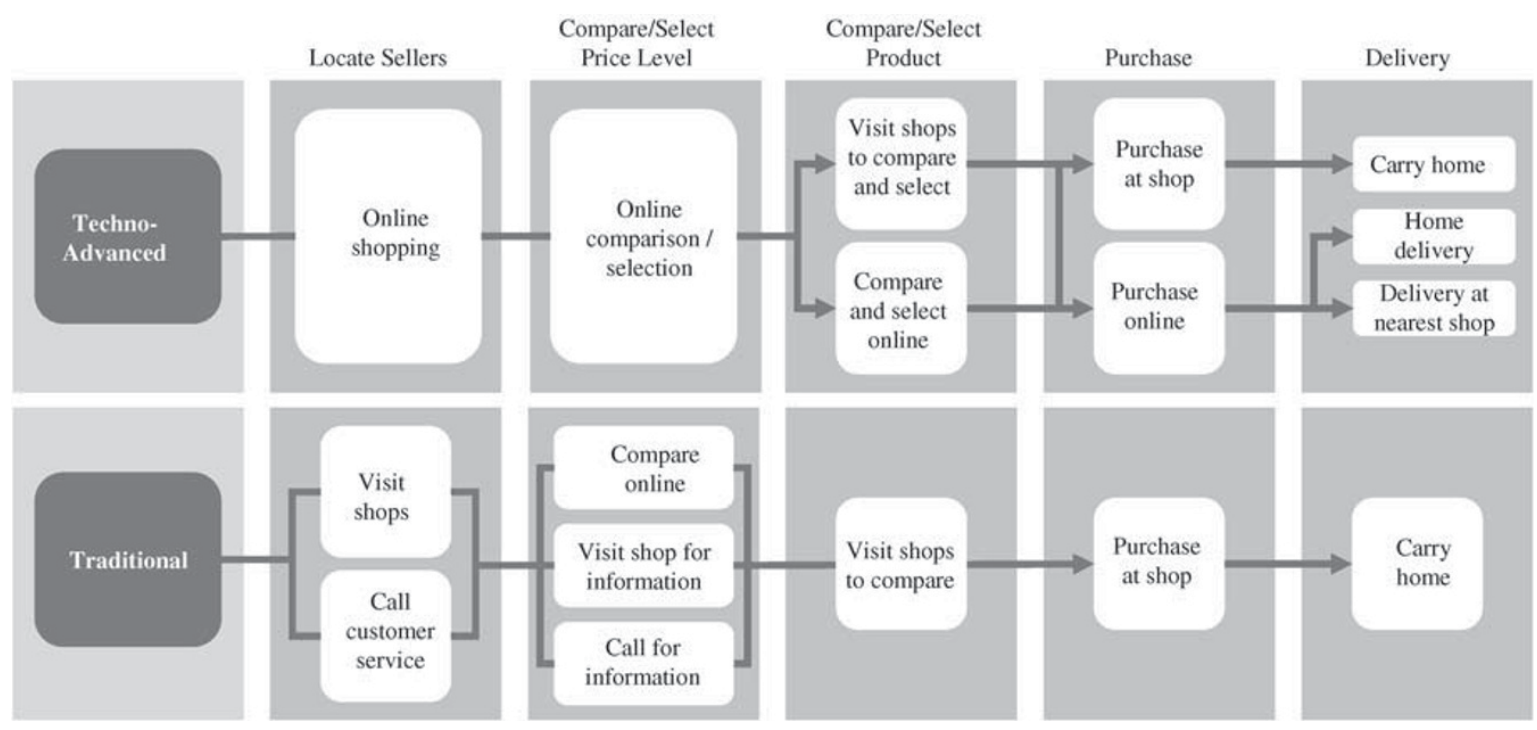

Figure 1: The customer buying journey. Source: Booz \& Company.

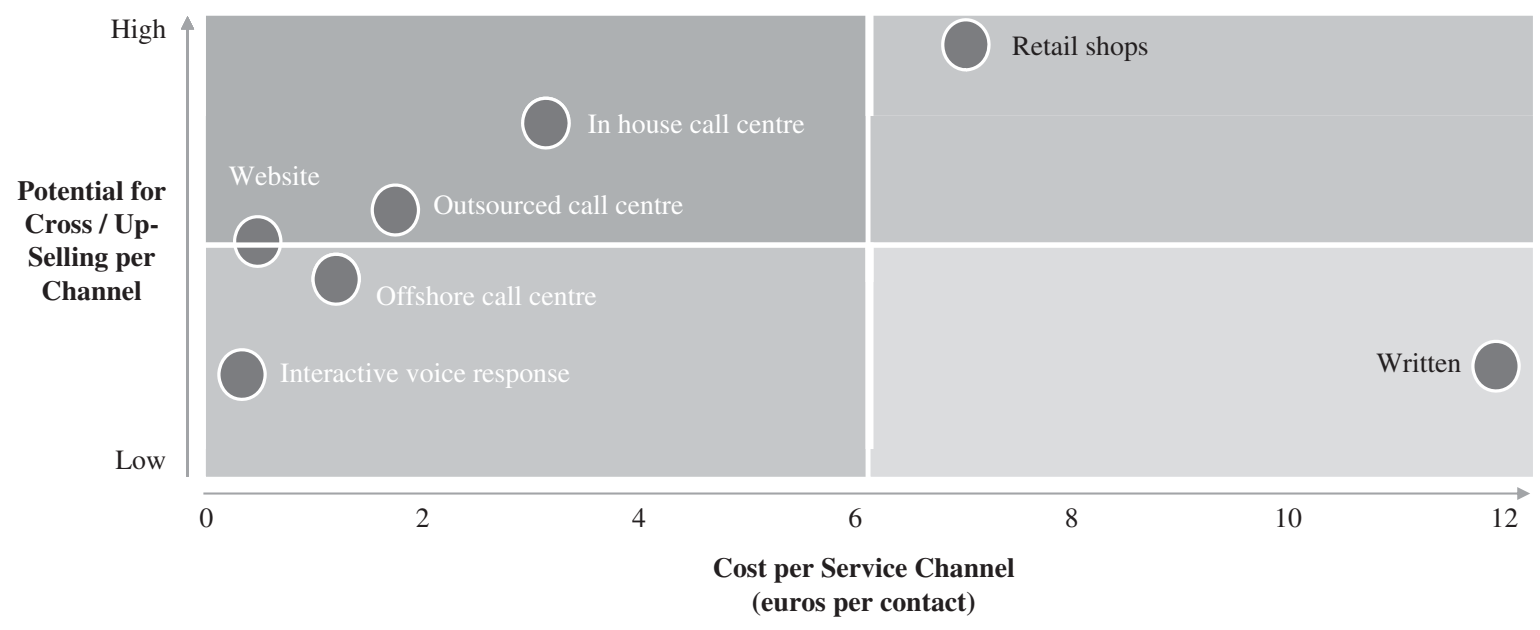

Figure 2: Cost and value creation potential of service channels.

Source: Booz \& Company.

Developing multi-channel capabilities also allows marketers to more efficiently steer customer interaction costs - from acquisition to service to retention - based on the value to the company of different customer segments. Clearly, cost-per-contact varies across channels (see Figure 2).

Interconnected marketing, sales and service touch points will invariably produce positive customer experiences; customers will feel valued and understood, and will be more likely to remain loyal and respond positively to cross-selling or up-selling approaches. ${ }^{3}$

\section{Building multi-channel capability}

Marketers can follow a four-step process to successfully integrate and orchestrate all customer channels. 


\section{'Channel journey' must be tailored to customer segment preferences and needs}

\section{Define the multi-channel strategy}

The first step to optimizing a multi-channel strategy is to explicitly define three key components:

- Customer segmentation

- The 'channel journey'

- Multi-channel incentive programmes

Marketers need to know their customers, including their preferences and spend potential, in order to tailor a differentiated multi-channel experience for each customer segment. A 'digital native' teenager with a limited budget may be most efficiently served by an onlineonly, no-touch channel, while a middle-aged, old-school shopper with deeper pockets and a preference for personal sales advice may warrant an extra outbound phone call or personalized written invitation to a product launch at the nearest retail outlet. Staff at any touch point should have easy access to this knowledge about their customers, coupled with the tools necessary to delight individual customers with any communication. This knowledge should similarly be embedded in electronic platforms that serve customers, whether online, in stores or via interactive voice response systems in call centres.

Secondly, companies need a detailed understanding of the 'channel journey' for each customer segment in order to identify what works most effectively (for generating sales and serving the customer) and efficiently (for controlling interaction costs). Pinpointing the most appropriate channel for each segment helps reduce costs, speed up the sales cycle and promote retention. Recent Booz \& Company research shows that when customers are offered product and service options they want, via the channel they prefer, they are more likely to be repeat buyers and less likely to perceive the interaction as intrusive.

Thirdly, senior management needs to define a clear incentive programme with targets and rewards that reflect and support the company's channel orchestration objectives. Only then will staff deliver customer value using an optimized channel mix, while management will have a lever to steer the customer's journey.

Clearly, there are trade-offs. A multi-channel solution will involve conflicts and channel cannibalization. Some business areas will lose out; the key is identifying the channels with the best ROI to ensure a positive net effect.

\section{Optimize online}

The online channel has matured into much more than simply the e-commerce website. A company's online presence is not just another stand-alone channel or brand booster platform: It is the linchpin of any multi-channel operation. The online channel is the sales and service hub, the tool that collects and disseminates the information that enables and facilitates the customer experience across all other channels. It acts as an umbrella that connects retail, e-commerce, 
CIOs must re-think IT architecture flexibility search engine marketing and search engine optimization. It funnels customers from social networking sites to sales and service touch points on and off the web.

Online channel capabilities can close gaps in the customer experience and facilitate sophisticated customer segmentation based on click stream transparency and rich web analytics. For instance, a marketing strategy that starts as an in-store promotion - collecting a coupon for an online competition - becomes a multi-channel experience when customers register online, and it affords marketing departments a valuable opportunity to capture and use key customer data.

\section{Build an IT foundation}

For most companies, building a highly automated, high-performance CRM IT architecture that integrates all customer touch points will be an evolutionary process, given the presence of already functioning single-channel operations that typically consist of inflexible, historically grown, more or less hardwired vertical silos. ${ }^{4}$

The remedy lies not in adding yet another channel tool, but in developing an open and flexible IT backbone that facilitates information flow across channels. Investment in business process management and integration technology may be painful in the short term and yield few visible 'same year' benefits. But if multi-channel capability is the goal, such a backbone is key to ensuring that the business rules that govern customer- and segment-specific channel experiences can be applied and extended seamlessly across an ever-growing range of customer touch points. Only then can marketing, sales and service organizations use predictive models or 'next best activity' engines, which provide sales and service agents with analytically grounded suggestions of what will meet individual consumer needs, to most effectively tailor offers and messages.

\section{Learn by example}

When it comes to making the most of multi-channel integration, companies need not reinvent the wheel and can learn much from looking at strategies being employed in industries beyond their own. From banking and insurance to telecommunications, travel and automotive, companies are exploring the opportunities that come from creating a cutting-edge, cross-channel customer experience.

Successful retailers are leveraging multiple touch points simultaneously to offer customers more choices along the buying journey. For example, one mobile operator installed interactive terminals in its retail outlets so that customers can preorder products and services. In this scenario, in-store personnel help build online customer profiles. Over time, shifting customers to online channels may cannibalize in-store sales, but it will help reduce overall customer interaction costs (since online interactions are less expensive), while providing a wealth of new opportunities to cross-sell and up-sell to those customers. 
Cross-functional effort can improve top line and drive cost streamlining
Much can be learned from the nimblest airlines as well. Some have mastered cross-channel integration to the point where a call centre agent can retrieve and complete a booking that a customer started online but abandoned (for whatever reason), and then called for personalized support to finish.

These and other best practices can be found in many retail industries, from banking, insurance and travel, to fashion, furniture and interior design. Identifying and applying them can help businesses avoid unnecessary duplication of efforts. Business ambitions should not be held back by a not-invented-here bias.

\section{Maximizing ROI}

Customers today have more buying and service channel choices than ever before. Linking and leveraging these customer touch points not only makes sense but is fast becoming a strategic necessity. This requires a coordinated effort among marketing, sales, service and IT executives, first to define who the customers are, secondly to collect information about them across all channels and thirdly to perform the analytics to match relevant products and services to customers' needs. The customer benefits from choice and better service. Businesses reduce the cost of sales by accurate, targeted marketing that has greater up- and cross-selling potential, and they can streamline cost-to-serve by better mapping different channels to customer segments.

With the results feeding directly to the bottom line, the question should be how quickly a company can roll out multi-channel customer management, and not whether it is necessary.

\section{References}

1. Moeller, L.H., Landry, E.C. and Kinni, T. (2009) The Four Pillars of Profit-driven Marketing: How to Maximize Creativity, Profitability, and ROI, McGraw-Hill, New York.

2. Peterson, M., Gröne, F., Kammer, K. and Kirscheneder, J. (2009) 'Performance-based advertising models: Extending the principles of profit-driven marketing', available at http:// www.booz.com/media/uploads/Performance_Based_Advertising_Models.pdf.

3. Hölbling, K., Künstner, T., Marsch, C. and Steinkrauss, N. (2009) 'Next-generation customer service: The new strategic differentiator', available at http://www.booz.com/media/uploads/ Next_Generation_Customer_Service.pdf.

4. Peterson, M., Koch, V., Gröne, F. and Vo, K. (2010) 'Online customers, digital marketing: The CMO-CIO connection', Journal of Direct, Data and Digital Marketing Practice, Vol. 11, No. 3, pp. 219-221. 